\title{
Accounting for Patterns of Wealth Inequality*
}

\author{
Lutz Hendricks \\ Iowa State University \\ CESIfo \\ Center for Financial Studies, Frankfurt
}

March 3, 2004

\begin{abstract}
The life-cycle model is a standard theoretical framework for studying savings and wealth inequality. This paper shows that life-cycle models have difficulties accounting for the empirical relationship between lifetime earnings and household wealth. Quantitative life-cycle models imply a far tighter relationship between earnings and wealth than is observed in U.S. data. As a result, life-cycle models greatly overstate wealth differences between earnings rich and earnings poor households while at the same time underpredicting wealth inequality among households with similar lifetime earnings. Incorporating several features thought to be important for understanding wealth inequality, in particular bequests and entrepreneurship, does not improve the model's ability to account for the data. These findings suggest that standard life-cycle theory fails to account for an important source of wealth inequality. JEL E2
\end{abstract}

\section{Introduction}

The life-cycle model pioneered by Fisher (1930) and Modigliani and Brumberg (1954) is commonly used to study consumption and saving behavior. Browning and Crossley (2001, p. 3) call it "the standard way that economists think about the intertemporal allocation of time, effort and money." In spite of some empirical challenges, life-cycle theory successfully accounts for a range of observations related to household saving and wealth (Browning and Crossley 2001). In particular, quantitative life-cycle models can replicate the observed distribution of wealth.

While early research found that life-cycle models failed to account for the largest wealth holdings (Huggett 1996), more recent work has developed model versions which are capable of matching the U.S. wealth distribution. Examples include Laitner (2002), who highlights the importance of altruistic bequests, and Quadrini (2000), who argues that entrepreneurs

\footnotetext{
${ }^{*}$ For helpful comments I am grateful to Jose-Victor Rios-Rull and to seminar participants at various institutions and conferences.
} 
account for the upper tail of the wealth distribution. Castaneda et al. (2003, hereafter CDR) find that life-cycle models can replicate observed wealth inequality, if the stochastic process governing income properly accounts for the top portion of the empirical income distribution.

The key determinants of household wealth in life-cycle models are labor earnings and age, possibly augmented by inheritances or self-employment income. Roughly speaking, life-cycle models predict that wealth-rich households are typically earnings-rich and near the age of retirement. The purpose of this paper is to make these predictions precise and to confront them with data. Specifically, the paper asks the following questions in the context of data and theory:

1. How tight is the relationship between retirement wealth and lifetime earnings?

2. How large are the wealth differences between earnings-rich and earnings-poor households?

3. How much wealth inequality remains after controlling for lifetime earnings and age?

These questions are meant to quantify the basic life-cycle intuition that lifetime earnings and age should be the main determinants of household wealth. To study these questions, I develop a quantitative life-cycle model which accounts for a large part of observed wealth inequality in the United States. The model's steady state is characterized by simulating a large sample of households. The empirical relationship between lifetime earnings and wealth is estimated using data from the Panel Study of Income Dynamics (PSID).

Findings: The main findings are summarized in table 1. The first row shows summary statistics for the PSID sample. The second row displays the corresponding model results. How these figures are constructed is described below. The empirical results qualitatively support the intuition suggested by life-cycle theory. Lifetime earnings and retirement wealth are strongly correlated. Earnings-rich households hold substantially more wealth than do earnings-poor households. Controlling for age and lifetime earnings substantially reduces wealth inequality. The Gini coefficients of retirement wealth within lifetime earnings deciles average 0.60 , compared with 0.75 in the entire sample.

However, quantitatively the implications of the life-cycle model differ substantially from the data. The correlation between retirement wealth and lifetime earnings is 0.9 in the model, compared with 0.6 in the data. Households in the 9th lifetime earnings decile hold 18 times more wealth (relative to their lifetime earnings) than do households in the second lifetime earnings decile. In the data, the corresponding ratio is less than 2 . The average Gini coefficient of retirement wealth within lifetime earnings deciles is 0.48 , compared with 0.60 in the data. While this gap is not that large, inspection of the wealth distribution within lifetime earnings deciles reveals that the model's implications are strongly at variance with the data. In the data, each lifetime earnings decile contains households with almost no wealth as well as households holding several multiples of average earnings. By 
contrast, in the model nearly all earnings rich households enter into retirement holding substantial wealth, while nearly all earnings poor households hold little wealth. One way of summarizing these findings is: The life-cycle model implies a tight relationship between lifetime earnings and retirement wealth which is not observed in the data.

[INSERT TABLE 1 HERE]

The intuition for these findings is as follows. A life-cycle model without earnings uncertainty predicts a perfect correlation between lifetime earnings and retirement wealth. Uncertain earnings break the perfect correlation because the timing of positive and negative earnings shocks differs among households with identical lifetime earnings. However, it is well-known from the literature that long-lived households can achieve a high degree of insurance against earnings shocks by holding assets. As a result, households with different earnings shocks but with similar lifetime earnings typically hold similar amounts of wealth.

The large differences in wealth between earnings-rich and earnings-poor model households are due to the presence of annuitized retirement income (Huggett 1996). Earnings poor households need little or no retirement wealth because their desired consumption is largely financed out of transfer income.

Robustness: The robustness of the results is checked in a number of ways. In the data, I restrict the samples to households with similar realizations of variables that could plausibly affect wealth for given lifetime earnings. The main findings remain valid among households with similar numbers of children, who were never divorced or self-employed, who do not hold stock and who did not inherit more than $\$ 1,000$.

In addition to the empirical robustness checks, I study several model extensions that have been proposed to help life-cycle models account for the observed concentration of wealth. These include alternative labor endowment processes and intergenerational transfers.

Inheritances could break the tight relationship between lifetime earnings and wealth implied by the life-cycle model. Inheritances also add a source of wealth heterogeneity among households with similar lifetime earnings. In fact, a number of previous studies suggest that bequests are important for understanding wealth inequality (De Nardi 2000; Laitner 2002). I therefore examine whether life-cycle models with accidental and intended bequests are more consistent with household wealth data. Since the literature has reached no consensus about the motives underlying bequest behavior, I consider two commonly used models. In the altruistic model parents value the utility flows of their children. In the joyof-giving or "warm glow" model parents derive utility from the act of giving (Abel 1987). ${ }^{1}$ In addition, the models feature accidental bequests. Regardless of the bequest motive, I find that bequests make almost no contribution towards accounting for the observed relationship between lifetime earnings and wealth.

\footnotetext{
${ }^{1}$ Additional theories have been proposed in the literature, but are difficult to implement in a quantitative model. Important examples include strategic bequests (Bernheim et al. 1985) and exchange motives (Cox and Rank 1992).
} 
Another potential reason why households with similar lifetime earnings may hold very different amounts of wealth is entrepreneurship (Quadrini 1999, 2000; Cagetti and De Nardi 2002). To study the importance of entrepreneurship, I develop a simple extension of the life-cycle model which is based on Cagetti and De Nardi (2002). I find that entrepreneurship substantially improves the model's ability to account for the empirical patterns reported in table 1. However, if the sample of households is restricted to those who were never selfemployed, the model's properties strongly resemble those of the baseline life-cycle model and the discrepancies between model and data resurface.

These findings lead me to conclude that life-cycle theory fails to account for an important reason why households with similar lifetime incomes choose to hold very different amounts of wealth near the age of retirement.

Related literature: Numerous papers have studied the implications of life-cycle models for wealth inequality. Instead of summarizing this literature, I refer the reader to CDR. Knowles and Postlewaite (2003) argue that the transmission of preferences from parents to children may be important for understanding wealth inequality.

The fact that households with similar characteristics hold very different amounts of wealth is well documented (e.g., Hurst et al. 1998). However, studies typically lack good measures of lifetime incomes. An exception is the recent work by Venti and Wise (2000) who measure lifetime incomes using Social Security earnings data. I draw heavily on their findings. One concern with their evidence is that Social Security earnings do not cover certain income types, introducing potentially large measurement error for some households. I therefore reexamine the issue using data from the Panel Study of Income Dynamics (PSID) where broader income concepts can be estimated. My findings confirm that households with similar lifetime incomes hold diverse amounts of wealth, even if samples are restricted to exclude sources of wealth heterogeneity not related to income.

The paper is organized as follows. Section 2 documents the empirical relationship between lifetime earnings and wealth in the PSID. A quantitative life-cycle model is developed in section 3 and compared with the data in section 4 . Section 5 extends the model to incorporate entrepreneurship. The final section concludes.

\section{Empirical Evidence}

\subsection{Data and sample description}

In this section, I describe the relationship between lifetime income and wealth in U.S. data. The data are drawn from 1968 to 1992 waves of the Panel Study of Income Dynamics (PSID) and from the PSID's wealth supplement. The notion of wealth is the PSID variable WEALTH2 which encompasses financial wealth, real estate including the main residence, business wealth, and the value of vehicles. ${ }^{2}$ Retirement wealth is the average of two wealth

\footnotetext{
${ }^{2} \mathrm{My}$ definition of wealth includes the value of pension plans accumulated in accounts. However in contrast to Venti and Wise (2000), no attempt is made to impute the value of defined benefit plans.
} 
observations between the ages of 50 and 65, discounted to age 60 using a discount rate of $4 \%$, which corresponds to the after-tax interest rate of the model economies.

Two definitions of earnings are considered. The narrow definition encompasses only wages and salaries received by the household head and by the spouse. The broad definition covers most forms of income other than interest and dividends that are reported in the PSID. It includes the PSID variable "total family money income" plus food stamps, lump sum payments received, and capital gains on the household's primary residence. Which concept is appropriate for comparisons with the model economies depends on the details of the models. The empirical findings are similar for both concepts.

Lifetime earnings are defined as the present discounted value of earnings between the ages of 25 and 65 . These are estimated for household heads using a fixed effect regression. Separate regressions are estimated for four education and sex classes. All time-invariant household characteristics are subsumed in the fixed effect. In the calculation of lifetime earnings, missing observations are replaced by their predicted values.

The sample selection criteria ensure that lifetime earnings and retirement wealth can be calculated for each household. Households are deleted, if they report fewer than two wealth observations between the relevant ages or if they report fewer than 15 earnings observations. The appendix describes the sample selection and the variable construction in more detail.

\subsection{Empirical Findings}

To characterize the relationship between wealth and lifetime earnings, I calculate the following summary statistics:

1. The correlation between retirement wealth and lifetime earnings in levels for all households $\left(C_{W E}\right)$ and in logarithms for households with strictly positive wealth $\left(C_{L W E}\right)$.

2. The Gini coefficient of retirement wealth within lifetime earnings decile $j, G i n i_{j}$. This measures how much wealth inequality remains after controlling for age and lifetime earnings.

3. The $90 / 20$ ratio of retirement wealth divided by lifetime earnings, $R_{90 / 20}$, which is calculated as follows. Denote the ratio of median retirement wealth to mean lifetime earnings for the $j$ th lifetime earnings decile by $x_{j}$. Then $R_{90 / 20}=x_{9} / x_{2}$. This ratio measures retirement wealth differences between earnings-rich and earnings-poor households.

Table 2 reports these summary statistics using the narrow earnings concept. Row 1 shows the baseline sample, while the remaining rows show sub-samples explained below. The findings are qualitatively consistent with the implications of life-cycle models:

1. Retirement wealth is strongly correlated with lifetime earnings: $C_{W E}=0.48$. 
2. Controlling for age and lifetime earnings reduces wealth inequality. The average of the Gini $_{j}$ coefficients across lifetime earnings deciles is 0.60 , compared with 0.70 to 0.75 in the full sample, depending on the year.

3. Earnings rich households hold more wealth relative to lifetime earnings: $R_{90 / 20}=$ 1.78 .

While these findings are qualitatively consistent with the predictions of standard lifecycle models, the analysis presented below shows that there are quantitative discrepancies. Life-cycle intuition suggests that controlling for age and lifetime earnings should eliminate a large part of total wealth inequality. The finding that the average Gini coefficient within lifetime earnings deciles is only around one-fifth smaller than in the entire sample therefore poses a potential challenge for theory.

[INSERT TABLE 2 HERE]

To get a better sense of what these numbers mean, figure 1 shows the Gini coefficients of retirement wealth for various lifetime earnings deciles. The broad pattern is consistent with the findings reported by Venti and Wise (2000), where the Gini coefficients decline from around 0.8 for the lowest decile to roughly 0.5 for the highest decile. In their study, lifetime earnings are calculated from Social Security earnings. The data are drawn from the Health and Retirement Study (HRS). ${ }^{3}$ The fact that neither the HRS nor the PSID over-sample rich households suggests that U.S. wealth may be even more concentrated than these numbers imply. ${ }^{4}$

[INSERT FIGURE 1 HERE]

One concern with Venti and Wise's findings is that Social Security earnings may not properly measure household incomes. Social Security earnings cover only labor earnings obtained from jobs that are subject to Social Security taxation, whereas the notion of earnings in life-cycle models encompasses all sources of non-capital income. Of particular concern is the omission of self-employment income. In addition, Social Security earnings are top-coded. ${ }^{5}$ As a result, Venti and Wise (2000) may sort households with very different lifetime incomes into the same lifetime earnings deciles, which could account for the large wealth dispersion shown in figure 1. Recalculating the results using the broad earnings concept helps address these concerns. As figure 1 shows, this has little effect on the Gini coefficients.

\footnotetext{
${ }^{3}$ A number of other authors have suggested that households with similar characteristics hold very different amounts of wealth (e.g., Hurst et al. 1998). However, Venti and Wise (2000) seem to be the first to formally document wealth inequality among households with similar lifetime earnings.

${ }^{4}$ The Gini coefficients are calculated on the basis of a Lorenz curve that is linearly interpolated between observed data points. It is assumed that the lowest wealth observation is zero and that the highest observation equals the 98th percentile. These assumptions imply that the approximate Gini coefficients are downward biased. I am grateful to Steven Venti for providing me with the data used in Venti and Wise $(2000)$.

${ }^{5}$ Venti and Wise (2000) clearly acknowledge both of these problems. The benefit of Social Security earnings is their accuracy.
} 
To complete the data description, figure 2 shows how median wealth holdings differ between lifetime earnings deciles. The findings obtained from the PSID are again similar to those of Venti and Wise (2000). ${ }^{6}$ The ratio of retirement wealth to lifetime earnings roughly doubles between the 2nd and the 9th lifetime earnings decile. With the broad income concept, the ratio roughly triples.

[INSERT FIGURE 2 HERE]

Robustness: Next I examine the robustness of these findings. In particular, I ask whether controlling for household characteristics which life-cycle models typically abstract from reduces wealth inequality amount households with similar lifetime earnings. A positive answer would suggest directions in which models might be extended. Venti and Wise (2000) conduct a similar analysis using a regression approach to control for household characteristics. Instead, I recalculate the summary statistics of table 2 based on samples comprising only households with similar characteristics. My findings are entirely consistent with those of Venti and Wise. ${ }^{7}$

Recent research suggests that entrepreneurship may be important for wealth inequality (Quadrini 2000, Cagetti and DeNardi 2002). Since standard life-cycle models do not explicitly capture entrepreneurship, it may be more appropriate to compare their implications with data on workers. However, deleting all households who owned a business or were self-employed in more than one year exacerbates the challenge for life-cycle theory. The correlation of retirement wealth and lifetime earnings declines. The Gini $i_{j}$ coefficients fall slightly, presumably because many high wealth households are dropped.

Expenditures on children or marital breakups may reduce retirement wealth for some households. However, excluding households whose head was ever divorced has little effect. Restricting the sample to households with one or two children reduces the Gini coefficient, but the sample size is small. Guvenen (2002) suggests that participation in the stock market may be important for wealth inequality. Yet deleting all households who hold more than $\$ 1,000$ of their retirement wealth in stocks does not reduce the Gini coefficients within lifetime earnings deciles. It does substantially reduce the correlation between lifetime earnings and retirement wealth as well as the 90/20 ratio. This presumably happens because the sample restriction eliminates many high wealth holders. Finally, dropping all households who report inheritances of more than $\$ 1,000$ has little impact. This finding should be interpreted with care because PSID households tend to underreport inheritances (Hendricks 2001).

Measurement error in either lifetime earnings or retirement wealth is an obvious concern. The robustness of the findings to alternative earnings measures and data sources suggests that measurement error in lifetime earnings is not a major concern. In particular, the fact that Venti and Wise (2000) obtain similar results based on administrative

\footnotetext{
${ }^{6}$ For ease of comparison, all series are scaled to match the median of Venti and Wise's data.

${ }^{7} \mathrm{I}$ also conducted a regression analysis similar to Venti and Wise's. Since the findings are similar to theirs, I do not report them in this paper.
} 
earnings data is reassuring. The degree of measurement error in wealth is more difficult to assess. However, note that measurement errors partially average out in the calculation of the $R_{90 / 20}$ and the Gini $_{j}$ coefficients. Moreover, the findings obtained from averaging two wealth observations are similar to those obtained from using only one wealth observation per household. Since the discrepancies between data and models turns out to be quite large, it appears unlikely that measurement error accounts for a large part of those discrepancies.

This analysis leads me to conclude that life-cycle models should account for three facts:

1. The correlation between lifetime earnings and retirement wealth is at most $C_{W E}=$ 0.6 .

2. The ratio of retirement wealth to lifetime earnings rises by a factor of at most 2 between the second and the 9 th lifetime earnings decile: $R_{90 / 20} \leq 2$.

3. The Gini coefficient of retirement wealth within lifetime earnings deciles is at least 0.5 .

It is, of course, not obvious that these facts pose challenges for life-cycle theory. Even households with identical lifetime earnings differ in the timing of earnings over their lifecycles and hence in their retirement wealth holdings. Only comparing the predictions of a quantitative model with the data can show that the observed degree of wealth inequality is robustly at variance with the predictions of life-cycle models. A model suitable for such a comparison is presented next.

\section{The Model}

The economic environment is a version of the stochastic incomplete markets life-cycle model commonly used to study the wealth distribution (e.g., Huggett 1996; CDR). ${ }^{8}$ The economy is inhabited by a continuum of households of unit mass, by a single representative firm, and by a government. All markets are competitive and the economy is in steady state.

\subsection{Households}

Each household consists of overlapping generations of parents and children. Each parent has one child which is born $T_{G}$ periods before the parent dies. Households age stochastically as in CDR. Each household lives through $a=1, \ldots, A$ "ages," each of which lasts a random number of periods. A household solves the following problem:

$$
\max E \sum_{t=1}^{T} \beta^{t} u\left(c_{t}\right)+\beta^{T} \psi \widehat{V}\left(k_{T+1}, e_{T+1}, q^{\prime}\right)
$$

\footnotetext{
${ }^{8}$ This section draws on Hendricks (2002) where a similar model is used to measure the contributions of accidental and intended bequests to observed bequest flows.
} 
subject to the budget constraint

$$
k_{t+1}=(1+r) k_{t}+w l_{t}-c_{t}+\tau\left(a_{t}\right)
$$

and the borrowing constraint $k_{t+1} \geq 0$. Here, $t$ indexes the date, $T$ is the household's stochastic lifetime, $r$ is the (constant) rate of return to capital, $w$ is the after-tax wage rate, $\tau\left(a_{t}\right)$ is a lump-sum transfer which depends on the age state $a_{t}$ described more fully below, and $l_{t}=h\left(a_{t}\right) e_{t} q$ is the household's labor endowment. The latter is the product of a permanent endowment $(q)$, a transitory endowment $\left(e_{t}\right)$, and a deterministic age-efficiency profile $h\left(a_{t}\right)$. During retirement $\left(a>a_{R}\right)$ the household does not work so that $l_{t}=0 . k$ denotes the household's wealth. The evolution of the random variables $e$ and $a$ is governed by exogenous Markov processes described in more detail below. The household values own consumption $(c)$ and, in case of death, the bequest left to his child according to the value function $\widehat{V}$. The parameter $\psi$ determines the intensity of the parent's bequest motive. The argument $q^{\prime}$ in the value function $\hat{V}$ denotes the child's random draw of the permanent labor endowment.

The household problem may be represented as a stationary dynamic program:

$$
\begin{aligned}
V(s)= & \max u(c)+\beta P_{s}(a) \sum_{a^{\prime}} P_{a}\left(a, a^{\prime}\right) \sum_{e^{\prime}} P_{e}\left(e, e^{\prime} ; a^{\prime}\right) V\left(s^{\prime}\right) \\
& +\beta\left(1-P_{s}[a]\right) \psi \sum_{q^{\prime}} P_{q}\left(q, q^{\prime}\right) \sum_{e^{\prime}} P_{e_{1}}\left(e^{\prime}\right) \hat{V}\left(k^{\prime}, e^{\prime}, q^{\prime}\right)
\end{aligned}
$$

subject to the budget constraint

$$
k^{\prime}(s)=(1+r) k(s)+w l(s)-c(s)+\tau(s)
$$

The timing of events within each period is as follows. At the beginning of the period the household is endowed with a state vector $s=(a, k, e, q)$. First, the household chooses current consumption $c(s)$ and savings $k^{\prime}=\kappa(s)$ subject to the budget constraint. Next, the household dies with probability $1-P_{s}(a)$. If the household survives, his next period age state, $a^{\prime}$, is drawn from the probability distribution $P_{a}\left(a, a^{\prime}\right)$. Either the household remains in age state $a$ or he moves to $a+1$. A new transitory labor endowment $e^{\prime} \in\left\{e_{1}, \ldots, e_{n_{e}}\right\}$ is drawn according to the Markov transition matrix $P\left(e, e^{\prime} ; a^{\prime}\right)$.

If the household dies, his terminal wealth $k^{\prime}$ is transferred to his child as a bequest. The child is born $T_{G}$ periods before the parent dies and starts life with $a=1$, with a transitory endowment drawn from the distribution $P_{e_{1}}$, and with a permanent labor endowment $q^{\prime} \in\left\{q_{1}, \ldots, q_{n_{q}}\right\}$ drawn according to the Markov transition matrix $P_{q}$.

Inheritances: The inheritance is determined as follows. In each period, a parent chooses the amount of capital to take into the next period, $k^{\prime}=\kappa(s)$. If the parent survives, $\kappa(s)$ will be his capital endowment tomorrow. However, if the parent dies, the child receives 
an amount $\hat{b}(\kappa)$ at age $T_{G}$, where the function $\hat{b}(\kappa)$ is given to the parent. For example, if inheritances are taxed at rate $\tau_{b}$ then each child inherits $\hat{b}(\kappa)=\left(1-\tau_{b}\right) \kappa$.

A more common specification in the literature assumes that parents and children do not overlap. However, this overstates the value of inheritances relative to households' lifetime earnings. In the data, inheritances are typically received around age 50, so that one dollar inherited has an age 20 present value of less than 40 cents with an interest rate of $4 \%$. Unfortunately, a model where parents and children overlap is computationally intractable, if parents are altruistic. The reason is that the parent's state vector then includes the child's state variables and vice versa.

To maintain tractability while correctly discounting inheritances, I impose informational assumptions that allow me to solve the household problem as if parents and children did not overlap. Specifically, I assume that the parent does not know his child's life history, even though the child has lived for a number of periods before the parent dies. Furthermore, I assume that the child learns at the beginning of life how much it will inherit from the parent and that the child can borrow against this inheritance. In other words, the child must know the realization of the parent's random lifetime events (such as earnings). Note that these assumptions are implied by models where parents and children do not overlap.

These assumptions allow me to solve the household problem as if the child were born after the parent's death. Instead of inheriting a random amount $\widehat{b}(\kappa)$ at age $T_{G}$, the child may be thought of as receiving a capital endowment of

$$
b(\kappa)=\widehat{b}(\kappa)(1+r)^{-T_{G}}
$$

at birth. Similarly, the parent values an inheritance as augmenting the child's age 1 capital endowment by $b(\kappa)$. This setup also affects the interpretation of the household's borrowing constraint. The household can borrow up to the present value of his future inheritance without violating the constraint $k_{t+1} \geq 0$.

The value function for bequests depends on the bequest motive. Since the reasons why parents leave bequests are not well understood, I consider three bequest motives that are common in the literature. If the household is selfish, then $\widehat{V}=0$. If the household has a joy-of-giving motive (Abel 1987), then utility is derived from the size of the inheritance:

$$
\widehat{V}\left(k^{\prime}, .\right)=b\left(k^{\prime}\right)^{1-\sigma^{*}} /\left(1-\sigma^{*}\right) .
$$

The value function in (5) implies that the parent cares not about the amount given, but about the amount received by the children. The functional form together with the restriction $\sigma=\sigma^{*}$ ensures that the ratio of bequests to consumption does not diverge in a growing economy. Finally, in the case of altruism, the value of the inheritance to the parent equals the child's value function at age 1:

$$
\widehat{V}\left(k^{\prime}, e^{\prime}, q^{\prime}\right)=V\left(1, b\left(k^{\prime}\right), e^{\prime}, q^{\prime}\right)
$$


First-order conditions: The first-order conditions for the household problem are given by

$$
u^{\prime}(c(s)) \geq P_{s}(a) \beta E V_{k}\left(s^{\prime}\right)+\left(1-P_{s}[a]\right) \beta \psi E \widehat{V}_{k}\left(s^{\prime}\right)
$$

with equality if $k^{\prime}>0$. Given the envelope condition $V_{k}(s)=(1+r) u^{\prime}(c(s))$, the Euler equation is given by

$$
\begin{aligned}
u^{\prime}(c[s]) \geq & P_{s}(a) \beta\left(1+r^{\prime}\right) \sum_{a^{\prime}} P_{a}\left(a, a^{\prime}\right) \sum_{e^{\prime}} P_{e}\left(e, e^{\prime} ; a^{\prime}\right) u^{\prime}\left(c\left[s^{\prime}\right]\right) \\
& +\left(1-P_{s}[a]\right) \beta \psi \sum_{q^{\prime}} P_{q}\left(q, q^{\prime}\right) \sum_{e^{\prime}} P_{e_{1}}\left(e^{\prime}\right) \widehat{V}_{k}\left(k^{\prime}, e^{\prime}, q^{\prime}\right)
\end{aligned}
$$

If the parent is altruistic, the marginal utility of leaving a bequest is given by

$$
\widehat{V}_{k}\left(k^{\prime}, e^{\prime}, q^{\prime}\right)=(1+r) u^{\prime}\left(c\left(1, b\left(k^{\prime}\right), e^{\prime}, q^{\prime}\right)\right) b^{\prime}\left(k^{\prime}\right) .
$$

In the case of joy-of-giving this becomes

$$
\hat{V}_{k}\left(k^{\prime}, .\right)=b^{\prime}\left(k^{\prime}\right) b\left(k^{\prime}\right)^{-\sigma^{*}} .
$$

\subsection{Firms}

A single representative firm solves a standard static profit maximization problem. It rents capital $K$ and labor $L$ from households so as to maximize $F(K, L)-q_{K} K-q_{L} L$, where $F$ is a constant returns to scale production function. Profit maximization requires that factor prices equal marginal products: $q_{K}=F_{K}(K, L)$ and $q_{L}=F_{L}(K, L)$.

\subsection{Government}

The government taxes labor income at a proportional rate and provides lump-sum transfers to retired households. The wage tax rate is $\tau_{w}$, so that the after-tax wage rate is given by $w=\left(1-\tau_{w}\right) q_{L}$. Bequests are taxed at the proportional rate $\tau_{b}$. Transfers are paid in equal amounts to all retired households. Hence, $\tau_{s}=0$ if $a(s) \leq a_{R}$ and $\tau_{s}=\tau_{R}$ otherwise, where $\tau_{R}$ is a constant. Aggregate transfer payments amount to $\int \Lambda(s) \tau_{s} d s$, where $\Lambda(s)$ denotes the density of households over states. Any excess tax revenues are used for government consumption $\left(C_{G}\right)$. The government budget constraint is therefore

$$
C_{G}+\int \Lambda(s) \tau(s) d s=\tau_{w} q_{L} L+\tau_{b} B
$$

where $B$ are aggregate bequest flows. The proportional estate tax is, of course, highly counterfactual. Its purpose is to capture the fact that a fraction of the estate is lost to death expenses and taxes. The total fraction lost to such expenses appears to be similar for rich and for poor households (see Hendricks 2001 for details). The assumption that the marginal tax rate is constant simplifies the analysis. 


\subsection{Equilibrium}

A stationary competitive equilibrium consists of aggregates $\left(K, L, C, C_{G}, B\right)$, a price system $\left(w, r, q_{K}, q_{L}\right)$, value functions $(V, \hat{V})$, policy functions $(c, \kappa)$, and a distribution over household types, $\Lambda(s)$, such that:

- The policy functions and value function solve the household problem.

- Firms maximize profits.

- Markets clear.

- The government budget is balanced.

- The distribution of household types, $\Lambda(s)$, is stationary.

- Inheritances, and therefore the initial capital endowments of households, are determined by 4 .

- Household prices are given by $w=\left(1-\tau_{w}\right) q_{L}$ and $r=q_{K}-\delta$.

The capital market clearing condition is $K=\int \Lambda(s) k(s) d s$. The labor market clears, if $L=\int \Lambda(s) l(s) d s$. The goods market clears if $F(K, L)+(1-\delta) K=C+C_{G}+K^{\prime}$. Aggregate consumption is given by $C=\int \Lambda(s) c(s) d s$. The aggregate bequest flow, $B$, equals the savings of all households who die in the current period.

\subsection{Discussion}

The treatment of inheritances and borrowing constraints deserve discussion. The most natural modeling approach would assume that parents and children learn about each other's earnings and ageing histories while they overlap. This would introduce strategic interaction. Unfortunately, it would also increase the size of the household's state vector by an unmanageable amount. A natural alternative would assume that children and parents cannot observe each other's histories. Children then receive a random inheritance drawn from the equilibrium distribution of bequests. Apart from complicating the household problem, it is not clear how to model borrowing constraints in this case. The common assumption that households cannot die in debt would rule out (almost) all borrowing. It would also be counterfactual. The approach pursued here permits household borrowing while keeping the state vector tractably short. Its main drawback is that the borrowing constraints facing young households are relaxed when bequests are larger. As a result, the model exaggerates the effect of bequests on the wealth distribution. Larger bequests increase the amounts borrowed by young households and thus increase wealth inequality.

A number of model extensions would be of interest, but are left for future research. For the majority of households, it is likely that investments in child human capital and, to a lesser extent, inter-vivos transfers constitute a large part of intergenerational transfers. 
Abstracting from these types of transfers is, however, not likely to affect the conclusions drawn about wealth-rich households, who account for the bulk of bequests. Evidence from estate tax records suggests that inter-vivos transfers are far smaller than bequests for rich parents (Joulfaian 1994).

\subsection{Model Parameters}

This section describes the choice of model parameters. I study a sequence of models, mainly to isolate the role played by various bequest motives:

1. The deterministic aging model resembles Huggett's (1996) model in that households are selfish and accidental bequests are redistributed by the government $\left(\tau_{b}=1\right)$. Households age deterministically $\left(\phi_{a}=1\right)$.

2. The no bequest model adds stochastic aging, as do all subsequent models to ease the computational burden.

3. The accidental bequest model also features selfish households, but accidental bequests are passed on to each household's children.

4. The joy-of-giving model adds a joy-of-giving motive, where the bequest parameter $\psi$ is chosen to match an inheritance-output ratio of $2.65 \%$.

5. The strong altruism model features altruistic parents who place as much weight on their children's welfare as on their own $(\psi=1) .{ }^{9}$ This is a natural benchmark case and places an upper bound on altruistic bequests. Even with $\psi=1$ the model falls slightly short of the target ratio of inheritances to output. This result is sensitive to alternative assumptions about earnings uncertainty and mortality rates, even though the findings reported below are robust.

Table 3 shows the parameters for the no bequest model. Most parameter choices follow Huggett (1996) which is a well-known benchmark model for the study of wealth inequality. The length of the model period is one year.

[INSERT TABLE 3 HERE]

Demographics: New households enter the model at physical age 20 (model age 1). In the data, inheritances are typically received around age 50. I therefore set the generation gap to $T_{G}=30$ years. Households live through $A=12$ phases. The first 3 phases represent the household's working life $\left(a_{R}=3\right)$. The transition probabilities $P_{a}$ are chosen such that these phases last on average 15 years each, corresponding to physical ages 20 to 64 . The remaining 9 phases represent retirement and last on average 3 years each.

\footnotetext{
${ }^{9}$ Strictly speaking, $\psi$ should be less than 1 because in growing economies children are richer than their parents. However, interpreting the model as the stationary transformation of a growing economy reduces $\psi$ only trivially from 1 to $\gamma^{1-\sigma}$, where $\gamma$ is the growth factor of output per worker.
} 
Mortality rates are taken from the Period Life Table, 1997, of the Social Security Administration. The first model deaths occur at the end of phase $a_{R}$, i.e. at the transition to retirement. The survival rate $P_{s}\left(a_{R}\right)$ is chosen to match the fraction of households surviving from age 20 to age 65 . During retirement, the mortality rate rises linearly with $a$ in a way that minimizes the deviation from observed survival probabilities at ages 70,75 , ..., 90. Figure 3 shows that the model is roughly consistent with observed survival rates in retirement.

These choices reflect a trade-off between computational simplicity and realistic mortality rates. Given this paper's focus on saving for retirement and bequests, matching life-expectancy during retirement appears crucial. Hence, retirement is divided into many short phases. Matching the duration of work life, on the other hand, appears less important and is computationally more costly. Below, I also present results for a model with deterministic aging (without intended bequests) and show that the findings are similar.

[INSERT FIGURE 3 HERE] [Survival rates]

Preferences: The period utility function has constant relative risk aversion: $u(c)=$ $c^{1-\sigma} /(1-\sigma)$. The curvature parameter $\sigma$ is set to a conventional value of 1.5 . The discount factor $\beta$ is chosen to match a capital-output ratio of 2.9 , which is the ratio of household wealth to income in the $1989 \mathrm{SCF}$. In the joy-of-giving model, I set the curvature of the bequest utility function equal to that of the period utility function $\left(\sigma^{*}=\sigma\right)$. This ensures that the model is consistent with balanced growth. ${ }^{10}$ The altruism parameter $\psi$ is either set to zero or chosen to match an estimate of the inheritance-output ratio.

Aggregate inheritance flows: Since the size of aggregate inheritances is important for some of this paper's findings, I review the evidence in some detail. The object of interest is the ratio of aggregate inheritances received from a previous generation to output. One approach measures inheritances reported by the children of deceased parents. Based on 1983-86 SCF data, Gale and Scholz (1994) estimate aggregate inheritance flows of $2.65 \%$ of GNP. Based on the 1989 SCF, Hendricks (2001) finds annual inheritances ranging from $1.1 \%$ to $1.9 \%$ of GNP for the years 1978 to 1987 .

An alternative approach estimates bequests as the product of wealth and mortality rates. Using this approach, Auerbach et al. (1999) arrive at a bequest-output ratio of $3.6 \%$ for 1990. Since their estimate includes death expenses, charitable donations and bequests to surviving spouses, who typically receive a large fraction of the estate value (Joulfaian 1994), inheritances of children and other relatives will be substantially smaller. Similar calculations that distinguish between singles and couples in the 1989 SCF imply inheritance flows between $2 \%$ and $2.7 \%$ of GNP, depending on assumptions about the fraction bequeathed when a surviving spouse is present (see Hendricks 2001 for details). The fact that inheritance data yield smaller figures than wealth and mortality data may reflect underreporting of inheritances.

\footnotetext{
${ }^{10}$ As written, the model abstracts from steady state growth, but may be interpreted as a scaled version of a growing economy.
} 
An indirect estimate of aggregate inheritance flows may be obtained from Joulfaian's (1994) sample of estate tax records. Aggregate net worth of the top 2.5\% of estates in 1982 is $\$ 45.9$ billion. Of this amount, $58.4 \%$ are distributed to surviving spouses, charity and death expenses, leaving $\$ 19$ billion ( $0.57 \%$ of GNP) to be distributed to children and other persons. Data on the size distribution of inheritances indicate that the top $2 \%$ of estates account for at least $60 \%$ of aggregate inheritances. Aggregate inheritance flows, excluding surviving spouses, then amount to at most $1.2 \%$ of GNP. ${ }^{11}$

Based on this evidence, I set the inheritance-output ratio to $2.65 \%$. Since most estimates are smaller than this value, my findings may overstate the importance of inheritances. Calibrating the model to match smaller inheritances would reinforce the conclusion that intended bequests are not important for the findings reported in this paper.

Labor endowments: The process governing labor endowments follows Huggett (1996). All households share the same permanent labor endowment $(q=1)$. The transitory endowment $(e)$ is drawn from a Markov chain with $n_{e}=6$ states. The transition matrix $P_{e}$ for working households $\left(a \leq a_{R}\right)$ approximates and $\mathrm{AR}(1)$ process with persistence 0.96 and a variance of the disturbance of 0.045 . The mean age-productivity profile $h(a)$ is estimated from 1990 PUMS data.

One concern is that this process understates the amount of earnings inequality because it is estimated from PSID data which fail to oversample the rich (see CDR). To address this concern, the sensitivity analysis considers alternative earnings processes which match the cross-sectional earnings dispersions estimated from SCF data.

Firms: The production function is Cobb-Douglas, $F(K, L)=\Xi K^{\alpha} L^{1-\alpha}$, with a capital share parameter of $\alpha=0.3$. The depreciation rate of capital is set to yield an after tax rate of rate of return of $r=0.04$ for a capital-output ratio of 2.9. The productivity parameter $\Xi$ is normalized to yield a wage rate of $q_{L}=1$.

Government policies: The wage tax rate is set to $\tau_{w}=0.4$ following Trostel (1993). Retirement transfers amount to $40 \%$ of mean household earnings (Castaneda et al. 2003). A similar ratio is obtained by computing the ratio of annuitized income to mean household earnings in the SCF, where annuitized income for the retired consists mostly of pensions, social security benefits and other retirement income (SCF variable 5722). The estate tax rate is set to $\tau_{b}=0.25$. For poor households, this captures death expenses of roughly $20 \%$ documented in Hurd and Smith (1999). For richer households, this represents in addition estate taxation.

\footnotetext{
${ }^{11} \mathrm{~A}$ number of studies convert intergenerational transfer flows into a stock and report the fraction of wealth due to intergenerational transfers (e.g., Gale and Scholz 1994). Such measures are highly sensitive to assumptions about discount rates and generation gaps.
} 


\section{Findings}

This section examines to what extent the quantitative life-cycle model developed in section 3 can account for the patterns of wealth inequality documented in section 2 .

\subsection{Properties of the Model Economies}

Before presenting the paper's new results, it is useful to ask whether the model economies imply realistic wealth and inheritance distributions.

\subsubsection{Wealth Distribution}

The first row of table 4 shows points on the Lorenz curve of net worth (including real estate, but excluding pension wealth) in the 1989 SCF (see Hendricks 2001 for details). Wealth holdings are highly concentrated among a small fraction of households. The top $1 \%$ of households own $36 \%$ of total wealth in the SCF, while the bottom $11.4 \%$ own negative or no wealth.

[INSERT TABLE 4 HERE]

The remaining rows of table 4 shows the wealth distributions implied by the model economies. Qualitatively, the results resemble those reported by Huggett (1996). In the deterministic aging model the fraction of households without wealth is somewhat larger than in data. This is due to young households who would like to borrow against future earnings. The Gini coefficient is smaller than in the data (0.74 versus 0.86 ). One reason is that the richest $1 \%$ of model households hold only $13 \%$ of aggregate wealth, compared with $36 \%$ in the data.

The no bequest model implies a very similar wealth distribution, suggesting that stochastic aging does not substantially alter the model's implications. The main difference compared with the deterministic aging model is that fewer households hold zero wealth. The reason is that borrowing when young incurs the risk of holding little retirement wealth in case worklife is short.

Both models exhibit the well-known failure of standard life-cycle models to account for the largest wealth observations (CDR). This shortcoming motivates some authors to incorporate bequests (e.g., Laitner 2002). There is some disagreement in the literature as to whether bequests are important for wealth inequality. In the model economies studied here, the answer depends on the bequest motive. Accidental and joy-of-giving bequests slightly increase the concentration of wealth. Bequests raise the fraction of households without wealth as young households borrow against future inheritances. As a result, the Gini coefficients rise relative to the no bequest model. However, the fraction of total wealth held by the richest households changes little. The strong altruism model does increase the fraction of total wealth held by the richest $1 \%$ of households to $18 \%$. However, this still falls short of the $35 \%$ figure found in the data. 


\subsubsection{Inheritance Distribution}

Next, I compare the size distribution of inheritances implied by alternative bequest motives with U.S. data. Table 5 shows the distribution of lifetime inheritances for a sample of households without surviving parents in the 1989 SCF. All inheritances ever received by either spouse are deflated and discounted to the year where the head is 50 years old. As the first row of table 5 reveals, the size distribution of lifetime inheritances is highly concentrated. While $70 \%$ of households receive very small or no inheritances, the top $2 \%$ of households receive almost $70 \%$ of aggregate inheritances. The concentration of inheritances in the PSID is similar, even though mean inheritances are smaller than in the SCF. ${ }^{12}$

The remaining rows of table 5 show that all of the model economies have difficulties accounting for the largest estates. While most of the models replicate the observation that $70 \%$ of households receive no or negligible inheritances, the top $2 \%$ of households receive less than $40 \%$ of aggregate inheritances. The implications of accidental and altruistic bequests are very similar. With joy-of-giving, the size distribution of inheritances is even less concentrated. The bottom $70 \%$ of households receive $38.3 \%$ of aggregate inheritances, compared with $0 \%$ in the data. Failing to account for the fact that most households receive no inheritances is a robust anomaly of the joy-of-giving specification with CRRA preferences. The intuition is that marginal utility of leaving a bequest is unbounded at zero.

[INSERT TABLE 5 HERE]

The model economies clearly fail to account for the highest wealth and estate observations. One reason, suggested by CDR, may be that the labor endowment process generates too few income rich households. Since the results reported in this paper focus on wealth inequality within lifetime earnings classes, this may not be a major concern. Nonetheless, the sensitivity analysis studies how increasing the dispersion of earnings to match the cross-sectional distribution observed in the SCF changes the model's implications.

\subsection{Wealth Inequality and Lifetime Earnings}

This section documents the paper's main result: life-cycle models imply a very tight relationship between retirement wealth and lifetime earnings. While there is too little wealth inequality among households with similar lifetime earnings, the wealth differences between lifetime earnings deciles are far too large in the model economies.

Recall that the data are characterized by large wealth inequality within lifetime income deciles and a fairly flat profile of the wealth to income ratio between lifetime income classes (see section 2). This observation challenges life-cycle models where wealth inequality is solely due to differences in age and earnings. By focussing on wealth at the outset of retirement and within a lifetime income decile both of these factors are held constant. Hence, wealth inequality arises only because households differ in the timing of earnings over

\footnotetext{
${ }^{12}$ Hendricks (2002) provides more detail and discusses the implications for the quantitative importance of accidental versus intended bequests.
} 
the life-cycle. This intuition suggests that life-cycle models should imply large differences in mean wealth between lifetime income classes, but small wealth dispersion within lifetime income classes, which is the reverse of the empirical pattern. The numerical simulations confirm this intuition.

Table 6 shows statistics summarizing the relationship between retirement wealth and lifetime earnings. The first row refers to the data and is repeated from table 2. The remaining rows show model economies without bequests. When calculating the statistics for the model economies, retirement wealth is calculated at age 65 and the "sample" is restricted to households who retire between ages 55 and 75 in order to eliminate artifacts introduced by stochastic aging. The statistics implied by the deterministic aging model are similar to those of the no bequest model, suggesting that the abstraction of stochastic aging does not distort the findings in important ways.

In both model economies, the correlation between retirement wealth and lifetime earnings is above 0.9 , compared with at most 0.6 in the data. Wealth differences between lifetime earnings classes are far too large. In the no bequest model, the $90 / 20$ ratio $\left(R_{90 / 20}\right)$ is 18, compared with less than 2 in the data. In the deterministic aging model, median retirement wealth in the 2 nd lifetime earnings decile is close to 0 , so that the $90 / 20$ ratio is near 600 . Figure 4 plots the ratio of retirement wealth to lifetime earnings for various lifetime earnings deciles. ${ }^{13}$ The discrepancy between model and data is striking.

One reason why earnings rich households save a larger fraction of their lifetime earnings for retirement is the presence of retirement transfers (Huggett 1996). Households with low lifetime earnings households finance most of their retirement consumption out of transfers and therefore hold little or even no retirement wealth. For earnings rich households, on the other hand, transfers finance only a fraction of retirement consumption.

[INSERT TABLE 6 HERE]

[INSERT FIGURE 4 HERE]

Figure 5 shows the Gini coefficients of wealth around the age of retirement for various lifetime earnings deciles. The data are repeated from figure 1 . The model economies match wealth inequality for the lowest 4 lifetime earnings deciles while understating the Gini coefficients for the higher earnings deciles. ${ }^{14}$ However, closer inspection reveals that the wealth distributions implied by the model economies are very different from their empirical counterparts, even for those lifetime earnings deciles where the models match the observed Gini coefficients.

[INSERT FIGURE 5 HERE]

Figures 6 through 8 show the retirement wealth distributions for the second, fifth and

\footnotetext{
${ }^{13}$ Observed retirement wealth is scaled to match the figure for households with median lifetime earnings in the no bequest model.

${ }^{14}$ Since neither the HRS nor the PSID over-sample rich households, it is likely that the empirical Gini coefficients are biased downwards. This magnifies the failure of the model economies to account for observed wealth inequality among households with similar lifetime earnings.
} 
ninth lifetime earnings deciles. ${ }^{15}$ To illustrate the interpretation, consider households in the 2 nd lifetime earnings decile shown in figure 6 . In the data, households in the second wealth decile hold very little wealth; the model economies replicate this fact. However, households in the ninth wealth decile hold around 4 times mean earnings (approximately $\$ 160,000$ in 1992). Model households own roughly half this amount.

A striking observation, highlighted by Venti and Wise (2000), is that each lifetime earnings decile in the data contains a substantial fraction of households holding very little wealth. Yet the richest $5 \%$ of households hold at least 400,000 dollars, even in the second earnings decile (the discrepancies are somewhat smaller in the PSID). The models make predictions that differ sharply from this. Within each lifetime earning class, the absolute differences between wealth rich and wealth poor households are far smaller than in the data. The model economies fail to account for the fact that a small fraction of households holds very large amounts of wealth in each lifetime earnings decile. Conversely, earnings rich model households are almost never wealth poor in retirement.

[INSERT FIGURES 6, 7, 8 HERE]

It is instructive to contrast scatter plots of log retirement wealth against log lifetime earnings for data and model economies. Figure 9 shows PSID data using the broad earnings definition. Figure 10 shows the same data for households in the no bequest model. Except for households with low lifetime earnings, the relationship between lifetime earnings and wealth is very tight. The modest correlation coefficient $C_{L W E}$ stems from a large number of low wealth households. This differs sharply from the data where wealth dispersion is much larger among households with moderate to high lifetime earnings.

[INSERT FIGURES 9, 10 HERE] [Scatter plots]

Taken together, these findings suggest that the model economies imply a tight relationship between retirement wealth and lifetime earnings, which is not found in the data. Households with similar lifetime earnings either choose to save different amounts or have additional sources of income that are not captured in either the life-cycle model or in the broad PSID earnings measure.

\subsection{Bequests}

Intergenerational transfers offer one possible explanation for wealth heterogeneity among households with similar lifetime earnings. Some households with low earnings receive large inheritances and therefore hold more wealth at retirement. Conversely, some earnings-rich households receive no inheritances and thus accumulate less wealth. However, the results shown in table 7 reveal that neither accidental nor intended bequests change the model implications significantly.

The accidental bequest model implies similar statistics to the no bequest model. Altruistic bequests slightly raise the Gini coefficients and lower the correlation between wealth and lifetime earnings, but exacerbate the wealth gaps between earnings rich and earnings

\footnotetext{
${ }^{15}$ To eliminate differences in the definitions of wealth, the PSID data are scaled to match mean wealth in Venti and Wise's (2000) data.
} 
poor households. Joy-of-giving reduces this gap, but further lowers the Gini coefficients. Neither bequest motive makes a substantial contribution towards overcoming the shortcomings of the no bequest model.

Figure 11 shows that the wealth differences between lifetime earnings classes are very similar for all bequest motives. Figure 12 displays the Gini coefficients within lifetime earnings deciles. Both figures are generally similar to those for the no bequest model. The main difference arises in the joy-of-giving case where low earnings households hold more wealth. The intuition is that even households with very low earnings wish to leave positive bequests and therefore enter into retirement with positive wealth. In addition, all households receive inheritances that help those with low earnings accumulate retirement assets.

I conclude that intergenerational transfers are not an important reason for retirement wealth inequality. Next, I discuss the intuition underlying this result.

[INSERT TABLE 7 HERE]

[INSERT FIGURE 11 HERE]

[INSERT FIGURE 12 HERE]

\subsubsection{Discussion}

An important part of the intuition is that inheritances are not a large source of lifetime income for the vast majority of households. In the accidental bequest model only $8.3 \%$ of households inherit more than $10 \%$ of lifetime earnings. With altruism the fraction increases to $15.8 \%$. These figures are likely higher than in the data. In the PSID only $2 \%$ of households report lifetime inheritances greater than $10 \%$ of lifetime earnings (see Hendricks 2001 for details). Since the PSID does not over-sample rich households, these estimates are likely downward biased. However, estate tax records suggest that even for the recipients of the largest bequests, inheritances constitute only a small fraction of lifetime resources. Joulfaian (1994) reports that for the largest $2.5 \%$ of estates the ratio of inheritances to household incomes is 3.2 . If lifetime incomes amount to 20 times annual income, then inheritances account for roughly $16 \%$ of lifetime resources.

Moreover, inheritances are partly consumed before retirement. The model households are buffer stock savers (Deaton 1992, Carroll 1997). They are sufficiently impatient to desire nearly flat age-consumption profiles. As a result, the young typically borrow against future inheritances in order to bridge the gap between low earnings and high desired consumption. Inheritances, therefore, do not have a strong effect on retirement wealth for most households.

To illustrate this reasoning, figure 13 shows simulated age-wealth profiles for households which experience median realizations of labor endowments and phase lengths in the strong altruism model. Wealth holdings are expressed as multiples of mean earnings. The households differ only in the amounts inherited, which are drawn from the 0th, 90th, 95th, and 99 th percentile of the inheritance distribution, respectively. Inheritances are reflected in the households' capital endowments at age 20 . 
The main findings is that a large part of inherited wealth is consumed before the household retires. The household without inheritance starts out with zero wealth at age 20. His wealth peaks at age 50 (which is the end of phase $a=2$ ) where the household owns twice average earnings. Thereafter, he starts to dissave until wealth reaches zero around age 85 . The household in the 95th percentile of the inheritance distribution receives 4 times mean earnings at age 20 , but starts to dissave immediately because earnings are low at young ages. As a result, his wealth at age 65 exceeds that of a household receiving no inheritance by only one-half of mean earnings. In this sense, more than $80 \%$ of the inheritance has been consumed by age 65 ; less than $20 \%$ remain to be passed on to the next generation. If households are selfish, the fractions consumed are even larger.

[INSERT FIGURE 13 HERE]

As a result, households who receive inheritances typically do not hold much more retirement wealth than those who do not. In the accidental bequest model, households in the 95th percentile of the inheritance distribution hold only $7.4 \%$ more wealth than households who inherited nothing. In the altruism model, the corresponding gap is $16.1 \%$. Of course, an additional fraction of the inheritance is consumed before the household dies.

These model predictions find some support in the PSID sample. Regressing retirement wealth on a lifetime earnings polynomial and on the present value of lifetime inheritances yields a coefficient on inheritances of -0.01 (s.e. 0.02). This means that retirement wealth is not larger for households who received higher inheritances, after controlling for lifetime earnings. Of course, this finding needs to be interpreted with caution given the quality of inheritance data. Still, the findings is consistent with the notion that a substantial fraction of inheritances is consumed before retirement.

The model economies therefore do not typically generate successive cohorts that leave larger and larger estates to their offspring, which is a common intuition for why altruistic bequests might contribute substantially to the emergence of large estates (De Nardi 2000). Instead, parents who received a large inheritance tend to leave a smaller bequest to their children. For example, consider the children with parents in the 95 th percentile of the inheritance distribution. In the accidental bequest model, these children inherit on average only $8.2 \%$ of their parents' inheritances. With altruism, this fraction is still only $10 \%$. The sensitivity shows that these findings remain valid if earnings are persistent across generations.

\subsection{Sensitivity Analysis}

This section examines the robustness of the findings to alternative assumptions about the labor endowment process.

\subsubsection{Intergenerational Persistence}

The baseline model abstracts from two potentially important features. First, earnings inequality is smaller than in the data because the process generating labor endowments is estimated from PSID data that fail to oversample the rich. Cross-sectional earnings 
inequality in the PSID is smaller than in the SCF (CDR). Second, labor endowments in the baseline model are not transmitted from parents to children, whereas in the data earningsrich parents have earnings-rich children. Both features could magnify the importance of bequests. If rich parents have rich children, estates may build up from one generation to the next, instead of being consumed by the children as in the baseline model.

Addressing both issues requires a stochastic process for labor endowments with a permanent component $(q)$ which is transmitted from parents to children. Without a permanent component it is difficult to simultaneously match earnings dispersion and intergenerational persistence statistics (see Hendricks 2003 for a discussion). Storesletten et al. (1998) estimate a suitable stochastic process for transitory labor endowments. The Markov chain governing $e$ approximates their process "D."

Realizations of $q$ are drawn from a three-state Markov chain. Its parameters match the cross-sectional Gini coefficient of earnings among working households in the SCF of 0.48 and a measure of the intergenerational persistence of lifetime earnings. Intergenerational persistence is measured by regressing log child lifetime earnings on log parent lifetime earnings. Based on the data reviewed in Hendricks (2003), the process for $q$ is chosen to generate a regression coefficient of 0.54 . This is also consistent with an intergenerational persistence of a five-year earnings average of 0.37 , which is well inside the range reported in the literature.

Findings: The findings are broadly similar to baseline model which abstracts from intergenerational persistence. Table 8 shows summary statistics for the model economies with accidental and with altruistic bequests. In both cases, the correlation between retirement wealth and lifetime earnings is above 0.9 . The wealth gaps between earnings rich and earnings poor households are even larger than in the accidental bequest model, largely because retirement wealth in the low lifetime earnings deciles is very close to 0 . Wealth inequality within lifetime earnings deciles is similar to the baseline model. I conclude that larger earnings dispersion and intergenerational persistence do not help the model economies account for patterns of wealth inequality.

[INSERT TABLE 8 HERE]

\subsubsection{Large Labor Endowments}

CDR suggest that a truncation of the labor endowment process prevented previous lifecycle models from matching observed wealth concentration. Typically labor endowment processes are estimated from panel data sets that do not oversample rich households. To avoid this truncation problem, CDR calibrate their model to match points on the crosssectional Lorenz curves for earnings and wealth estimated from SCF data. The resulting labor endowment process has two components. The lowest $n_{e}-1$ labor endowments follow a process that resembles the autoregressive processes commonly estimated from panel data. The top endowment is large (100 times larger than the next endowment) and reached with a very small probability. One interpretation is that this represents entrepreneurial

opportunities. With this process, CDR's model matches the cross-sectional income and 
wealth distributions.

Endowing the life-cycle model with such an earnings process may help account for wealth inequality among households with similar lifetime earnings. A small fraction of households receives very large earnings draws. Since these are transitory, a large part will be saved. Heterogeneity among households in the timing of these shocks could break the tight relationship between lifetime earnings and retirement wealth found in the baseline model.

Since replicating CDR's calibration method is computationally expensive, I implement a simple version of what I view as the key features of their approach. The model retains the labor endowment process of the baseline case, but adds one large endowment state with index $n_{e}$. The probability of staying in this state is taken from CDR (80.5\%). Also based on their probability matrix, I assume that the transition probability from state $n_{e}$ to all other states is the same. I deviate from their process in setting the probability of entering state $n_{e}$. In CDR's calibration, the probability of entering state $n_{e}$ ranges from 0 to $0.02 \%$. As a result, only $0.04 \%$ of households attain state $n_{e}$. Accurately solving for the equilibrium allocation then requires simulating a very large number of households. I therefore raise the probability of entering state $n_{e}$ to $0.1 \%$, but set it to 0 for states below the median. The resulting process has $0.2 \%$ of households in the top labor state. Similar to CDR, the top labor endowment level is chosen to match the fraction of wealth held by the top $5 \%$ of households. In table 9 , this process is labeled "CDR 1."

An earlier working paper version of CDR presented a slightly different endowment process, where the probability of staying in state $n_{e}$ was zero. I consider this case as well and label it "CDR 2." I view this calibration as an inexpensive way of capturing the key features of CDR's endowment process.

[INSERT TABLE 9 HERE]

Findings: The results shown in table 9 reveals the same discrepancies relative to data that were found in all previously studied model economies. Wealth gaps between earnings rich and earnings poor households are even larger than in the baseline model. The reason is that high lifetime earnings deciles contain households who received the rare high earnings draws and saved large fractions. The correlation between lifetime earnings and retirement wealth drops to 0.78 with the CDR 2 process, whereas it remains above 0.9 in the case of CDR 1. Both correlations are still far above their empirical counterparts.

The Gini $_{j}$ coefficients increase to levels that are close to those observed in the data. However, as in the baseline model, inspection of the wealth distributions within lifetime earnings deciles reveals large discrepancies compared with the data. Figure 14 illustrate these discrepancies for households in the 2nd lifetime earnings decile. The model wealth distributions are compressed relative to the empirical distributions. They strongly resemble the distributions implied by the baseline accidental bequest model.

I conclude that adjusting the labor endowment process to encompass occasional high earnings draws does not significantly improve the model's overall ability to account for 
observed patterns of wealth inequality. While some of the model statistics improve (notably the $G i n i_{j}$ coefficients), other discrepancies compared with the data are exacerbated. The relationship between lifetime earnings and retirement wealth remains far tighter than in the data.

This finding is not surprising. Households solve exactly the same problem as in the accidental bequest model, except for a small probability of drawing a very large labor endowment. But since this low probability event is never realized for households outside of the top lifetime earnings deciles, their saving behavior does not change much.

[INSERT FIGURE 14 HERE]

\section{Entrepreneurship}

The previous discussion suggests that a more drastic departure from the life-cycle framework is needed to account for the observed relationship between wealth and lifetime earnings. One model extension that has received much attention in recent research is entrepreneurship. Empirical studies suggest that entrepreneurship may be an important source of wealth inequality (Quadrini 1999). Results from quantitative general equilibrium models support this view (Quadrini 2000; Cagetti and De Nardi 2002). In order to explore the implications of entrepreneurship, this section extends the baseline model in the simplest possible way so as to accommodate self-employment.

Two features of the baseline model are modified. (i) Households randomly receive selfemployment opportunities. (ii) Households are assumed to be selfish in order to simplify the computations. The results of the previous section suggest that abstracting from intended bequests is not an important limitation. In all other respects the model is identical to the baseline no bequest model. The model is also similar to that of Cagetti and De Nardi (CDN, 2002) who argue that their model can account for the U.S. wealth distribution.

\subsection{Households}

The household problem of the baseline model is modified as follows. Each household enters into the period endowed with a state vector $s=(a, k, \theta, e, q)$, where $\theta \in\left\{1, \ldots, N_{\theta}\right\}$ denotes entrepreneurial productivity. Those endowed with $\theta \geq \theta_{E}$ have the opportunity to invest capital in an entrepreneurial project; I call these households entrepreneurs. All others are called workers.

\subsubsection{Self-Employment Opportunities}

An entrepreneurial project offers the opportunity to invest capital $k_{E}$ in order to produce output according to the production function $G\left(k_{E}, \theta\right)=\Theta(\theta) k_{E}^{\nu}$, where $\Theta(\theta)$ denotes the level of self-employment productivity associated with endowment $\theta$. I assume $\nu<1$ so that entrepreneurial production yields positive profits.

The evolution of $\theta$ over time is governed by a Markov chain with transition matrix $P_{\theta}\left(\theta, \theta^{\prime} ; a\right)=\operatorname{Pr}\left(\theta^{\prime} \mid \theta, a\right)$. Following CDN, I assume that retired households cannot start new projects, even though they may continue existing ones. New households inherit their 
$\theta$ endowments from their parents according to the same transition matrix.

Since entrepreneurial income is received in the current period, entrepreneurs maximize current period profits by solving

$$
\pi(s)=\max G\left(k_{E}, \theta\right)-q_{K} k_{E}
$$

subject to borrowing constraint

$$
k_{E} \leq k+B(s)
$$

The function $B(s)$ specifies how much the household may borrow in each state $s$. Its key feature is that wealth rich agents can invest more in self-employment opportunities: $B_{k}(s)>0$. This provides an incentive for the self-employed to save a large fraction of their incomes and helps the model match the observed concentration of wealth (see Quadrini 2000 for a discussion).

The optimal input choices are denoted by $k_{E}(s)$. These are characterized by the firstorder condition $G_{k} \geq q_{K}$ with equality if the borrowing constraint does not bind. The optimal capital input is given by

$$
k_{E}^{1-\nu}=\min \left\{k+B(s), \Theta(\theta) \nu / q_{K}\right\}
$$

This specification is similar to CDN's. It abstracts from two potentially important features: self-employment is not risky and does not take time. That is, self-employment yields a safe income in the current period. This permits to embed the self-employment decision into the household problem as a simple, static profit maximization problem. Essentially, selfemployment provides the household with a random high income state. In accounting for the wealth distribution, it plays a similar role to the high income labor state in CDR. The only difference is due to the borrowing constraint: households with higher capital stocks receive higher self-employment incomes.

\subsubsection{The Household Problem}

The household problem may be represented by the Bellman equation

$$
V(s)=\max u(c)+P_{s}(a) \beta E V\left(s^{\prime}\right)
$$

subject to the budget constraint

$$
k^{\prime}(s)=y(s)-c(s)
$$

where income consists of profits, capital income, earnings, and transfers:

$$
y(s)=\pi(s)+(1+r) k(s)+w l(s)+\tau(a)
$$

Retired households with $a>a_{R}$ do not receive labor earnings $(l(s)=0)$. For those not self-employed $\pi(s)=0$. The expected value next period is given by

$$
E V\left(s^{\prime}\right)=\sum_{a^{\prime}} P_{a}\left(a, a^{\prime}\right) \sum_{e^{\prime}} P_{e}\left(e, e^{\prime} ; a^{\prime}\right) \sum_{\theta^{\prime}} P_{\theta}\left(\theta, \theta^{\prime} ; a^{\prime}\right) V\left(s^{\prime}\right)
$$


This differs from the baseline model only in the addition of the term which determines the value of $\theta^{\prime}$. Optimal consumption is characterized by the Euler equation

$$
u^{\prime}(c(s)) \geq P_{s}(a) \beta E\left\{u^{\prime}\left(c\left(s^{\prime}\right)\right)\left[1+r+\pi_{k}\left(s^{\prime}\right)\right]\right\}
$$

or, expanding the expectations operator:

$$
\begin{aligned}
u^{\prime}(c(s)) \geq & P_{s}(a) \beta \sum_{a^{\prime}} P_{a}\left(a, a^{\prime}\right) \sum_{e^{\prime}} P_{e}\left(e, e^{\prime} ; a^{\prime}\right) \sum_{\theta^{\prime}} P_{\theta}\left(\theta, \theta^{\prime}, a^{\prime}\right) \times \\
& u^{\prime}\left(c\left[s^{\prime}\right]\right)\left[1+r+\pi_{k}\left(s^{\prime}\right)\right]
\end{aligned}
$$

with equality if $k^{\prime}>0$. Note that the rate of return on capital includes a term, $\pi_{k}\left(s^{\prime}\right)=$ $\partial \pi\left(s^{\prime}\right) / \partial k^{\prime}$, reflecting the effect of the capital stock on self-employment income. This term equals zero for states of the world where the household is not self-employed or where the borrowing constraint does not bind. This problem nests the household problem of the baseline model without intended bequests as a special case by setting $\Theta(\theta)=0$ for all $\theta$.

\subsection{Competitive Equilibrium}

In addition to households, the economy is inhabited by a representative firm and a government. Both are identical to the baseline model. Denote the firm's factor demands by $K_{C}$ and $L_{C}$. The definition of a competitive equilibrium is the similar to that of the baseline model, except for the market clearing conditions. Denote the set of states where households are self-employed by $\Gamma_{E}$ and its complement by $\Gamma_{W}$. Let $\Gamma=\Gamma_{E} \cup \Gamma_{W}$. Labor market clearing requires $L=L_{C}$, where $L$ denotes aggregate labor supply in efficiency units. Capital market clearing requires $K=K_{E}+K_{C}$, where capital demand by entrepreneurs is given by

$$
K_{E}=\int_{s \in \Gamma_{E}} \Lambda(s) k_{E}(s) d s
$$

Total output consists of production by firms and by entrepreneurs, which is given by

$$
Y_{E}=\int_{s \in \Gamma_{E}} \Lambda(s) G\left(k_{E}(s), \theta(s)\right) d s
$$

Output is used for government consumption, household consumption, and investment which is given by

$$
X=\int_{s \in \Gamma} \Lambda(s)\left[k^{\prime}(s)-(1-\delta) k(s)\right] d s
$$

The market clearing conditions for goods is therefore

$$
F\left(K_{C}, L_{C}\right)+Y_{E}=C_{G}+X+\int_{s \in \Gamma} \Lambda(s) c(s) d s
$$




\subsection{Calibration}

The choice of self-employment parameters is loosely based on CDN and summarized in table 10. There are $N_{\theta}=2$ self-employment states. $\theta=1$ represents no self-employment opportunity so that $\Theta(1)=0$. $\Theta(2)$ matches the fraction of total income received by self-employed households of $19.6 \% .{ }^{16}$ The curvature parameter $\nu$ matches the fraction of wealth held by the richest $5 \%$ of households. Setting $\nu$ such that the model replicates the Gini coefficient of self-employment income estimated from the SCF (0.67) yields similar results.

The transition matrix for $\theta$ is chosen to replicate entry and exit rates into and out of self-employment over 1 and 10 year periods as well as the fraction of self-employed among non-retired households (14\%). In the data, exit rates decline with self-employment experience. Since the model features time-invariant entry and exit rates, it understates turnover at high frequencies, while overstating turnover at low frequencies. For example, the annual entry rate into self-employment is $3.4 \%$ in the data versus $1.8 \%$ in the model. The 10 year exit rate is $40 \%$ in the data and $63 \%$ in the model. Similar findings are obtained from imposing the transition matrix used by CDN which matches annual mobility rates only.

The borrowing constraint is specified in the simplest way that captures two key features: (i) $B(s)$ is increasing in $k$, reflecting the notion that entrepreneurs can use wealth as collateral. (ii) Even households without wealth can borrow. Specifically, I assume that entrepreneurs can borrow a fraction of average earnings plus their own capital:

$$
B(s)=\omega\left[k(s)+\int_{\bar{s} \in \Gamma} w l(\bar{s}) \Lambda(\bar{s}) d \bar{s}\right]
$$

The parameter $\omega$ is set to yield $K_{E} / K=0.4$ (Quadrini 2000). Like most borrowing constraints in quantitative life-cycle models, this specification is ad hoc, but sufficient to permit the model to match the wealth concentration observed in U.S. data. ${ }^{17}$ The remaining parameters are chosen as in the baseline model without self-employment.

[INSERT TABLE 10 HERE] [Parameters of self-employment model]

Cross-sectional wealth distribution: Entrepreneurship substantially improves the model's ability to account for the observed concentration of wealth. Without bequests, the richest $1 \%$ of households holds $25 \%$ of wealth, compared with $35 \%$ in the SCF. The Gini coefficient of wealth of 0.86 is the same as in the SCF.

The model greatly overstates the fraction of households holding no wealth $(19 \%$ vs. $12 \%$ in the SCF). The reason is that households in the self-employment model are more

\footnotetext{
${ }^{16}$ Quadrini's (1999) estimate is $22 \%$. Details of how self-employment statistics are estimated are provided in the appendix.

${ }^{17} \mathrm{CDN}$ derive the borrowing constraint such that entrepreneurs are indifferent between repaying and defaulting, in which case they keep a fraction of the invested capital. This is theoretically more satisfying, but has the unappealing implication that earnings rich households face tigher borrowing constraints than do earnings poor households.
} 
impatient than in the no bequest model without self-employment. The calibration algorithm chooses the discount factor to match the observed level of household wealth (more precisely: $K / Y$ ). Since self-employment gives households an additional incentive to save, a lower discount factor is required in order to match the same aggregate wealth level. All of these findings are consistent with CDN. Accidental bequests slightly increase wealth inequality because young households borrow against future inheritances.

\subsection{Findings}

Incorporating entrepreneurship into the life-cycle model leads to the following main findings: Entrepreneurship helps the model replicate some features of the data that pose challenges for the life-cycle models studied so far. However, the problems of the baseline model resurface when a complete measure of household income is used. In particular, the self-employment model predicts a very tight relationship between lifetime earnings and retirement wealth if earnings include self-employment profits or if the sample of households is restricted to those never self-employed. This finding contrasts with the data presented in section 2 for the PSID's broad earnings measure and for households who never selfemployed.

Lifetime earnings and wealth: Table 11 shows summary statistics that characterize the relationship between lifetime earnings and retirement wealth. For comparison, the table also shows statistics for the no bequest model and for the PSID sample. In my discussion, I focus on the self-employment model without bequests. As table 11 reveals, accidental bequests do not change the findings very much.

While all of the models studied so far implied very high correlations between lifetime earnings and wealth, the self-employment model yields a correlation of only 0.35 ; this is actually lower than the PSID estimate. The 90/20 ratio is still far larger than in the data, but much smaller than in the no bequest model. Wealth inequality within lifetime earnings deciles increases dramatically. The average Gini coefficient is 0.76 , compared with 0.60 in the PSID.

The self-employment model also accounts for high wealth holdings in low lifetime earnings deciles. As noted before, all of the models studied so far imply very small wealth gaps between wealth rich and wealth poor households within the lower lifetime earnings deciles. In the self-employment model, these gaps are far larger than in the data.

All of these changes go in the direction of improving the match between model and data, although some go too far. It is possible that a parameterization which attaches less weight to self-employment would further improve the model's ability to account for the data. Self-employment appears to break the counterfactually tight relationship between lifetime earnings and retirement wealth found in all previous models. The intuition for this finding has three parts:

1. Self-employment acts like large, transitory earnings shocks. The timing and duration of these shock varies across households. Since entrepreneurs have high saving rates, 
this has a substantial effect on the retirement wealth distribution.

2. Using the narrow definition of earnings (in the model and in the data) fails to capture self-employment income, which is an important component of lifetime income for some households.

3. In part, wealth inequality among households with similar lifetime earnings reflects differences between workers and entrepreneurs.

This intuition suggests that the tight relationship between lifetime earnings and wealth may resurface when a broader measure of earnings is used or when the sample is restricted to workers.

\section{[INSERT TABLE 11 HERE]}

Workers: Consider first the implications of restricting the sample to households who were never self-employed ("workers") shown in table 12 (see section 2 for details on the PSID sample). Except for the much lower correlation coefficient, the PSID results are similar to the full sample.

The model statistics are qualitatively similar to those of the no bequest model without self-employment. The lifetime earnings-wealth correlation of 0.78 is far higher than in the data. The $90 / 20$ ratio is very high, mainly because low earnings workers hold very little wealth (recall that $19 \%$ of model households hold no wealth). The model generates large wealth Gini coefficients within lifetime earnings deciles. However, in contrast to the full sample, this is due to the large fraction of workers holding no wealth. The model fails to generate high wealth households in low earnings deciles. This is in marked contrast to both the PSID and to Venti and Wise's (2000) data, as illustrated in figure 15 for the 2nd lifetime earnings decile.

It is perhaps not surprising that the findings are so similar to no bequest model. Workers solve exactly the same problem as in that model, except that the option of future selfemployment is added. This leads households to save more. However, this is more than offset by the fact that households are less patient, which leads them to save less. As a result, the wealth distribution among workers is compressed relative to the no bequest model.

[INSERT TABLE 12 HERE]

[INSERT FIGURE 15 HERE]

Broad earnings concept: Next, consider the implications of measuring lifetime earnings using the broad definition of earnings shown in table 13. For the PSID, I use the broad earnings concept defined in section 2. For the model, I add profits to labor earnings.

The shortcomings of the baseline no bequest model resurface now that lifetime earnings are properly measured. The wealth gap between earnings rich and earnings poor households is far larger than in the data. The $90 / 20$ ratio is near 20 in the model relative to 3.3 in the PSID. The correlation between lifetime earnings and wealth is far too high (0.84, compared 
with 0.54 in the PSID). It appears at first that the model does better in terms of replicating the relationship between $\log$ lifetime earnings and $\log$ retirement wealth. However, a scatter plot reveals that the modest correlation is due to the large number of households holding almost no wealth. Deleting households with wealth below $2 \%$ of annual earnings increases the correlation coefficient to 0.74 , which is again substantially higher than in the data.

These findings lead me to conclude that introducing self-employment into the lifecycle model does not resolve the model's main shortcomings. When income is properly measured, all of the model economies studied here imply (i) a tight relationship between lifetime income and retirement wealth and (ii) large wealth differences between earnings rich and earnings poor households. The data do not support these predictions. This suggests either that the life-cycle model omits a large source of income or that it fails to account for an important reason why households with similar lifetime incomes choose to save very different amounts.

Robustness: Which model extensions could help reconcile the self-employment model with the data? Clearly, the modeling and calibration of self-employment are the least well understood model elements. However, it is important to note that the model's counterfactual implications arise from the savings decisions of workers who were never self-employed. Aside from the possibility of future self-employment opportunities, these workers solve a perfectly standard life-cycle consumption-savings problem. Attempting to account for wealth inequality within lifetime income classes by modifying the modeling of self-employment opportunities or borrowing constraints is therefore not promising. What is needed is a modification of the problem solved by the majority of households who are never self-employed.

\section{Conclusion}

The life-cycle model is the standard theoretical framework for thinking about savings and wealth inequality. Versions of the model successfully account for a range of empirical observations, including the cross-sectional wealth distribution observed in U.S. data. This paper highlights three discrepancies between life-cycle theory and data which suggest that the model fails to account for an important source of wealth inequality:

1. The relationship between lifetime earnings and wealth is far tighter in the model than in the data. The correlation coefficient is above 0.9 in the model compared with at most 0.6 in a sample of PSID households.

2. Wealth differences between earnings rich and earnings poor households are too large in the model by roughly a factor of 10 .

3. The model understates wealth inequality among households with similar lifetime earnings and ages. 
In life-cycle theory, wealth inequality is due to differences in earnings and age. Extended models accommodate additional sources of income, such as inheritances and selfemployment income. The theory predicts that households with similar ages and lifetime incomes should hold similar amounts of wealth. This prediction is shown to be robust against model extensions that help life-cycle theory account for the observed concentration of wealth, including intergenerational transfers and entrepreneurship. The main finding of the present paper is that this prediction does not find support in the data.

This finding lead me to conclude that life-cycle theory omits an important source of wealth inequality. Either a large source of lifetime income is not captured in the model and in the data, or households with similar lifetime incomes choose to save different amounts. 


\section{Appendix}

\subsection{Data and Empirical Implementation}

This section describes the procedures underlying the data reported in section 2. A sample of households is extracted from the 1968 to 1992 waves of the PSID, which meets the following criteria. A household's identity is determined by the household head. Each household must report at least 15 years of all relevant income concepts for both head and spouse (if present). Two wealth observations must be reported between the ages of 50 and 65 .

All dollar figures are converted into constant prices using a CPI deflator. Since the model should be thought of as a stationary transformation of a growing economy, all dollar figures are also divided by a constant growth trend of $0.14 \%$ per year (Huggett 1996). Present values discount to age 60 using a $4 \%$ interest rate.

The present value of household earnings is calculated as follows. For each household, a predicted age income profile covering ages between 25 and 65 is computed by regressing household income on an age quadratic. Regressions are run separately for different education and sex classes of the household head. From the household specific intercept together with the predicted age profile, the household's present value of lifetime income is calculated.

Self-employment statistics: Entry and exit rates for self-employment are calculated from a sample of household heads in the PSID who are between the ages of 20 and 65 . A household is considered self-employed, if the head reports being self-employed in his/her main job. None of the findings change substantially if self-employment is defined instead as ownership of a business, even though entry and exit rates are somewhat different (Quadrini 1999). Households are included in the sample, if they report at least 15 earnings observations and two wealth observations for the head.

The transition matrix $P_{\theta}$ is chosen to minimize the weighted deviations from entry and exit rates over one and ten years as well as the fraction of households who are self-employed $(14 \%)$. The $n$-year entry rate is the fraction of households who are not self-employed in year $t$ and who are self-employed in year $t+n$. The exit rate is the fraction of those self-employed in year $t$ who are not self-employed in year $t+n$. These definitions do not take into account whether the household was self-employed between dates $t$ and $t+n$.

\subsection{Computational Algorithm}

The household problem is solved by backward induction. The policy functions $c(s)$ and $\kappa(s)$ are approximated on a 100 point grid for the capital stock via linear interpolation.

To compute the equilibrium, the algorithm simulates a single long dynasty consisting of $T=30,000$ households. The stationary distributions of variables are approximated by their distributions over this dynasty's history. Aggregate quantities are calculated by summing over dates. For example, aggregate consumption is computed as $C=T^{-1} \sum_{t=1}^{T} c_{t}$ 
where $c_{t}$ denotes the amount consumed by an individual member of the stand-in dynasty at date $t$. When computing the aggregate capital stock, it is necessary to correct this expression for the fact that young agents borrow their initial capital endowments using their future inheritances as "collateral." When summing over the time path of capital holdings, $k_{0}(1+r)^{i}$ must be subtracted from each agent's capital stock prior to age $T_{G}$ because this amount is borrowed from another agent. 


\section{Tables}

\begin{tabular}{|l|r|r|r|}
\hline & $C_{W E}$ & Mean Gini & $R_{90 / 20}$ \\
\hline PSID & 0.48 & 0.60 & 1.78 \\
Model & 0.91 & 0.47 & 18.02 \\
\hline
\end{tabular}

Table 1: Wealth and lifetime earnings.

Notes: $C_{W E}$ is the correlation coefficient between lifetime earnings and retirement wealth. Mean Gini denotes the average Gini coefficient of retirement wealth within lifetime earnings deciles. $R_{90 / 20}$ is the ratio of retirement wealth relative to lifetime earnings for the 9 th versus the 2 nd lifetime earnings decile.

\begin{tabular}{|l|r|r|r|r|r|}
\hline & $C_{W E}$ & $C_{L W E}$ & Mean Gini & $R_{90 / 20}$ & $N$ \\
\hline Baseline sample & 0.48 & 0.51 & 0.60 & 1.78 & 1466 \\
Never self-employed & 0.22 & 0.47 & 0.53 & 2.05 & 910 \\
Never divorced & 0.49 & 0.52 & 0.60 & 1.81 & 1293 \\
One/two children & 0.30 & 0.52 & 0.54 & 2.00 & 376 \\
No stock holdings & 0.16 & 0.40 & 0.63 & 0.98 & 1055 \\
No inheritance & 0.52 & 0.53 & 0.60 & 1.91 & 1164 \\
\hline
\end{tabular}

Table 2: PSID summary statistics.

Notes: $C_{L W E}$ is the correlation coefficient between ln lifetime earnings and $\ln$ retirement wealth among households with positive retirement wealth. $N$ denotes the sample size. The remaining column headings are defined in table 1 . 


\begin{tabular}{|l|l|}
\hline Households & \\
\hline$\beta=0.958$ & Matches $K / Y=2.9$ \\
$\sigma=1.5$ & Huggett $(1996)$ \\
\hline Demographics & \\
\hline$A=12$ & Number of life-cycle phases \\
$a_{R}=3$ & Work phases corresponding to ages 20-65 \\
$P_{S}$ & Matches mortality rates of couples. Social \\
& Security Administration, Period Life Tables \\
& 1997 \\
$P\left(a, a^{\prime}\right)$ & Matches mean phase length of 15 years for \\
& work life and 3 years for retirement \\
$T_{G}=30$ & Children are born $T_{G}$ periods before parents \\
& die \\
\hline Firms & Capital income share in NIPA \\
\hline$\alpha=0.30$ & Matches after-tax interest rate of 4 percent \\
$\delta_{k}=0.063$ & Normalized such that $q_{L}=1$ \\
$\Xi=0.93$ & \\
\hline Government & Trostel (1993) \\
\hline$\tau_{w}=0.40$ & See text \\
$\tau_{b}=0.25$ & CDR \\
$T r / Y=0.40$ & \\
\hline
\end{tabular}

Table 3: Parameter values for the no bequest model.

\begin{tabular}{|l|r|r|r|r|r|r|r|r|r|r|r|}
\hline Pct. class & $\mathbf{2 0}$ & $\mathbf{4 0}$ & $\mathbf{6 0}$ & $\mathbf{8 0}$ & $\mathbf{9 0}$ & $\mathbf{9 5}$ & $\mathbf{9 9}$ & $\mathbf{1 0 0}$ & Gini & Frac=0 & Frac $<\mathbf{0}$ \\
\hline SCF & -4.2 & -2.9 & 2.7 & 16.2 & 29.8 & 41.8 & 64.1 & 100.0 & 0.86 & 4.1 & 7.3 \\
Determ. aging & 0.0 & 0.5 & 5.5 & 23.2 & 45.0 & 62.9 & 87.0 & 100.0 & 0.74 & 24.5 & 0.0 \\
No bequest & 0.0 & 0.7 & 5.3 & 22.1 & 42.9 & 60.6 & 86.0 & 100.0 & 0.75 & 12.6 & 0.0 \\
Accid. bequest & -2.3 & -1.6 & 3.1 & 20.4 & 41.7 & 59.9 & 85.8 & 100.0 & 0.79 & 10.1 & 6.9 \\
Joy-of-giving & -5.4 & -3.9 & 3.5 & 22.1 & 43.4 & 61.3 & 86.5 & 100.0 & 0.80 & 1.8 & 22.3 \\
Strong altruism & -7.0 & -6.7 & -3.1 & 12.6 & 33.6 & 52.6 & 82.1 & 100.0 & 0.91 & 9.9 & 10.8 \\
\hline
\end{tabular}

Table 4: Wealth distribution.

Notes: The table shows the cumulative fraction of aggregate wealth held by each percentile class.

\begin{tabular}{|l|r|r|r|r|r|r|r|}
\hline Pct. class & $\mathbf{7 0}$ & $\mathbf{8 0}$ & $\mathbf{9 0}$ & $\mathbf{9 5}$ & $\mathbf{9 8}$ & $\mathbf{1 0 0}$ & I/Y \\
\hline SCF & 0.0 & 1.8 & 9.4 & 18.9 & 30.8 & 100.0 & 1.3 \\
Accid. bequest & 0.6 & 4.7 & 19.7 & 39.6 & 62.1 & 100.0 & 1.1 \\
Joy-of-giving & 38.3 & 48.1 & 62.5 & 74.3 & 84.9 & 100.0 & 2.6 \\
Strong altruism & 1.6 & 6.9 & 22.7 & 42.0 & 63.8 & 100.0 & 2.4 \\
\hline
\end{tabular}

Table 5: Inheritance distribution.

Notes: Inheritances are expressed as multiples of mean earnings per household. The 
table shows the cumulative fraction of total inheritances received by each percentage class. $\mathrm{I} / \mathrm{Y}$ denotes the inheritance-output ratio.

\begin{tabular}{|l|r|r|r|r|}
\hline & $C_{W E}$ & $C_{L W E}$ & Mean Gini & $R_{90 / 20}$ \\
\hline PSID & 0.48 & 0.51 & 0.60 & 1.78 \\
Determ. aging & 0.93 & 0.79 & 0.46 & 587.93 \\
No bequest & 0.91 & 0.66 & 0.47 & 18.02 \\
\hline
\end{tabular}

Table 6: Model economies without bequests.

Notes: The column headings are defined in table 1.

\begin{tabular}{|l|r|r|r|r|}
\hline & $C_{W E}$ & $C_{L W E}$ & Mean Gini & $R_{90 / 20}$ \\
\hline PSID & 0.48 & 0.51 & 0.60 & 1.78 \\
Accid. bequest & 0.91 & 0.68 & 0.45 & 15.18 \\
Joy-of-giving & 0.91 & 0.82 & 0.39 & 6.72 \\
Strong altruism & 0.90 & 0.68 & 0.49 & 19.25 \\
\hline
\end{tabular}

Table 7: Model economies with bequests.

Notes: The column headings are defined in table 1.

\begin{tabular}{|l|r|r|r|r|}
\hline & $C_{W E}$ & $C_{L W E}$ & Mean Gini & $R_{90 / 20}$ \\
\hline PSID & 0.48 & 0.51 & 0.60 & 1.78 \\
Accid. bequest & 0.91 & 0.68 & 0.45 & 15.18 \\
IGP & 0.96 & 0.70 & 0.42 & 52.90 \\
IGP. Altruism & 0.93 & 0.63 & 0.48 & 102.44 \\
\hline
\end{tabular}

Table 8: Alternative labor endowment processes.

Notes: The column headings are defined in table 1. IGP refers to the model economy with intergenerational persistence and accidental bequests. IGP Altruism denotes the model economy with altruistic bequests.

\begin{tabular}{|l|r|r|r|r|}
\hline & $C_{W E}$ & $C_{L W E}$ & Mean Gini & $R_{90 / 20}$ \\
\hline PSID & 0.48 & 0.51 & 0.60 & 1.78 \\
Accid. bequest & 0.91 & 0.68 & 0.45 & 15.18 \\
CDR 1 & 0.94 & 0.64 & 0.55 & 25.15 \\
CDR 2 & 0.78 & 0.66 & 0.59 & 34.72 \\
\hline
\end{tabular}

Table 9: Alternative labor endowment processes.

Notes: The column headings are defined in table 1. CDR 1 denotes the model economy with a labor endowment process based on CDR. CDR 2 features a similar process where the highest endowment state is transitory. 


\begin{tabular}{|l|l|}
\hline Households & \\
\hline$\beta=0.925$ & Matches $K / Y=2.9$ \\
\hline Entrepreneurs & \\
\hline$\theta=[0.00,0.59]$ & Matches aggregate self-employment income \\
$\nu=0.81$ & $\begin{array}{l}\text { Matches fraction of wealth held by richest } 5 \\
\text { percent of households }\end{array}$ \\
$\omega=0.04$ & Matches $K_{E} / K=0.40$ \\
\hline
\end{tabular}

Table 10: Parameter values for the self-employment model.

Notes: Other parameters are the same as in the no bequest model.

\begin{tabular}{|l|r|r|r|r|}
\hline & $C_{W E}$ & $C_{L W E}$ & Mean Gini & $R_{90 / 20}$ \\
\hline PSID & 0.48 & 0.51 & 0.60 & 1.78 \\
No bequest & 0.91 & 0.66 & 0.47 & 18.02 \\
SE No bequest & 0.35 & 0.51 & 0.76 & 10.84 \\
SE Accidental bequest & 0.36 & 0.53 & 0.74 & 8.36 \\
\hline
\end{tabular}

Table 11: Self-employment model. All households.

Notes: The column headings are defined in table 1 .

\begin{tabular}{|l|r|r|r|r|}
\hline & $C_{W E}$ & $C_{L W E}$ & Mean Gini & $R_{90 / 20}$ \\
\hline PSID & 0.22 & 0.47 & 0.53 & 2.05 \\
No bequest & 0.91 & 0.66 & 0.47 & 18.02 \\
SE No bequest & 0.78 & 0.61 & 0.65 & 105.50 \\
SE Accidental bequest & 0.80 & 0.63 & 0.62 & 50.37 \\
\hline
\end{tabular}

Table 12: Self-employment model. Workers.

Notes: The column headings are defined in table 1 .

\begin{tabular}{|l|r|r|r|r|}
\hline & $C_{W E}$ & $C_{L W E}$ & Mean Gini & $R_{90 / 20}$ \\
\hline PSID & 0.54 & 0.65 & 0.58 & 3.31 \\
No bequest & 0.90 & 0.65 & 0.48 & 16.47 \\
SE No bequest & 0.84 & 0.61 & 0.63 & 19.19 \\
SE Accidental bequest & 0.84 & 0.63 & 0.60 & 12.88 \\
\hline
\end{tabular}

Table 13: Self-employment model. Broad earnings concept.

Notes: The column headings are defined in table 1. 


\section{References}

[1] Abel, Andrew B. (1987). "Operative Gift and Bequest Motives." American Economic Review 77(5): 1037-47.

[2] Auerbach, Alan J.; Jagadeesh Gokhale; Laurence J. Kotlikoff; J. Sabelhaus; David Weil (1999). "The Annuitization of Americans Resources — A Cohort Analysis." Mimeo.

[3] Bernheim, B. Douglas; Andrei Shleifer; Lawrence H. Summers (1985). "The strategic bequest motive." Journal of Political Economy. 93(6): 1045-76.

[4] Browning, Martin; Thomas, F. Crossley (2001). "The life cycle model of consumption and saving." Journal of Economic Perspectives 15(3): 3-22.

[5] Cagetti, Marco; Mariacristina De Nardi (2002). "Entrepreneurship, Frictions, and Wealth." Mimeo. University of Minnesota.

[6] Carroll, Christopher D. (1997). "Buffer-stock saving and the life cycle/permanent income hypothesis." Quarterly Journal of Economics 112(1): 1-56.

[7] Castaneda, Ana; Javier Diaz-Giminez; Jose-Victor Rios-Rull (2003). "Accounting for the U.S. Earnings and Wealth Inequality." Journal of Political Economy 111(4): 81857.

[8] Cox, Donald; Mark R. Rank (1992). "Inter-Vivos Transfers and Intergenerational Exchange." Review of Economics and Statistics 74(2): 305-314.

[9] Deaton, Angus (1992). Understanding Consumption. Oxford. Clarendon Press.

[10] De Nardi, Mariacristina (2000). "Wealth inequality and intergenerational links." Mimeo. Federal Reserve Bank of Chicago.

[11] Diaz-Giminez, Javier; Vincenzo Quadrini; Jose-Victor Rios-Rull (1997). "Dimensions of inequality: Facts on the U.S. distributions of earnings, income, and wealth." Federal Reserve Bank of Minneapolis Quarterly Review, Spring: 3-21.

[12] Fisher, Irving (1930). The Theory of Interest. New York: MacMillan.

[13] Gale, William G.; John K. Scholz (1994). "Intergenerational Transfers and the Accumulation of Wealth." Journal of Economic Perspectives 8(4): 145-60.

[14] Guvenen, M. Fatih (2002). "Reconciling Conßicting Evidence on the Elasticity of Intertemporal Substitution: A Macroeconomic Perspective." Mimeo. University of Rochester.

[15] Hendricks, Lutz (2001). "Bequests and Retirement Wealth in the United States." Mimeo. Iowa State University.

[16] Hendricks, Lutz (2002). "Intended and Accidental Bequests in a Life-cycle Economy." Mimeo. Iowa State University.

[17] Hendricks, Lutz (2003). "The intergenerational persistence of lifetime earnings." Mimeo. Iowa State University.

[18] Huggett, Mark (1996). "Wealth distribution in life-cycle economies." Journal of Monetary Economics 38: 469-94.

[19] Hurd, Michael; James P. Smith (1999). "Anticipated and Actual Bequests." Mimeo. 
Rand.

[20] Hurst, Erik; Ming Ching Luoh; Frank Stafford (1998). "Wealth Dynamics of American Families: 1984 - 1994." Brookings Papers on Economic Activity 1.

[21] Joulfaian, David (1994). "The distribution and division of bequests: Evidence from the collation study." Mimeo. Office of Tax Analysis.

[22] Knowles, John; Andrew Postlewaite (2003). "Wealth inequality and parental transmission of savings behavior." Mimeo. University of Pennsylvania.

[23] Laitner, John (2002). "Wealth Accumulation in the U.S.: Do Inheritances and Bequests Play a Significant Role?" Mimeo. University of Michigan.

[24] Modigliani, F.; R. Brumberg (1954). "Utility Analysis and the Consumption Function: An Interpretation of Cross-Section Data," in Post-Keynesian Economics. Kurihara, K., ed. New Brunswick: Rutgers University Press, pp. 388-436.

[25] Mulligan, Casey B. (1997). Parental priorities. Chicago: University of Chicago Press.

[26] Quadrini, Vincenzo (1999). "The Importance of Entrepreneurship for Wealth Concentration and Mobility." Review of Income and Wealth 45(1): 1-19.

[27] Quadrini, Vincenzo (2000). "Entrepreneurship, Saving and Social Mobility." Review of Economic Dynamics 3(1): 1-40.

[28] Trostel, Philip A. (1993). "The effect of taxation on human capital." Journal of Political Economy 101(2): 327-50.

[29] Venti, Steven F.; David A. Wise (2000). "Choice, Chance, and Wealth Dispersion at Retirement." NBER working paper \#7521. 